\title{
Article
}

\section{Burnout of Healthcare Workers Amid the COVID-19 Pandemic: A Follow-Up Study}

\author{
Yoshito Nishimura ${ }^{1,2, *}$,, Tomoko Miyoshi $^{1}$, Asuka Sato ${ }^{3}$, Kou Hasegawa ${ }^{1}$, Hideharu Hagiya ${ }^{1}$, \\ Yoshinori Kosaki ${ }^{4}$ and Fumio Otsuka ${ }^{1}$ (D)
}

check for updates

Citation: Nishimura, Y.; Miyoshi, T.; Sato, A.; Hasegawa, K.; Hagiya, H.; Kosaki, Y.; Otsuka, F. Burnout of Healthcare Workers Amid the COVID-19 Pandemic: A Follow-Up Study. Int. J. Environ. Res. Public Health 2021, 18, 11581. https:// doi.org/10.3390/ijerph182111581

Academic Editors: Andrea Fiorillo, Maurizio Pompili and Gaia Sampogna

Received: 11 September 2021 Accepted: 2 November 2021 Published: 4 November 2021

Publisher's Note: MDPI stays neutral with regard to jurisdictional claims in published maps and institutional affiliations.

Copyright: (c) 2021 by the authors. Licensee MDPI, Basel, Switzerland. This article is an open access article distributed under the terms and conditions of the Creative Commons Attribution (CC BY) license (https:// creativecommons.org/licenses/by/ $4.0 /)$.
1 Department of General Medicine, Okayama University Graduate School of Medicine, Dentistry and Pharmaceutical Sciences, Okayama 7008558, Japan; tmiyoshi@md.okayama-u.ac.jp (T.M.); khasegawa@okayama-u.ac.jp (K.H.); hagiya@okayama-u.ac.jp (H.H.); fumiotsu@md.okayama-u.ac.jp (F.O.)

2 Department of Medicine, John A. Burns School of Medicine, University of Hawai'i, Honolulu, HI 96822, USA

3 Center for Graduate Medical Education, Okayama University Hospital, Okayama 7008558, Japan; asukasato@okayama-u.ac.jp

4 Center for Education in Medicine and Health Sciences, Okayama University Graduate School of Medicine, Dentistry and Pharmaceutical Sciences, Okayama 7008558, Japan; pj4w35pr@s.okayama-u.ac.jp

* Correspondence: nishimura-yoshito@okayama-u.ac.jp

\begin{abstract}
The coronavirus disease 2019 (COVID-19) pandemic has posed a significant challenge to the modern healthcare system and led to increased burnout among healthcare workers (HCWs). We previously reported that HCWs who engaged in COVID-19 patient care had a significantly higher prevalence of burnout (50.0\%) than those who did not in November 2020 (period 1). We performed follow-up surveys in HCWs in a Japanese national university hospital, including basic demographics, whether a participant engaged in care of COVID-19 patients in the past 2 weeks, and the Maslach Burnout Inventory in February 2021 (period 2) and May 2021 (period 3). Periods 1 and 3 were amid the surges of COVID-19 cases, and period 2 was a post-surge period with a comparatively small number of COVID-19 patients requiring hospitalization. Response rates to the surveys were 33/130 $(25.4 \%)$ in period $1,36 / 130(27.7 \%)$ in period 2 , and $56 / 162(34.6 \%)$ in period 3 , respectively. While no consistent tendency in the prevalence of burnout based on variables was observed throughout the periods, the prevalence of burnout tends to be higher in periods 1 and 3 in those who engaged in COVID-19 patient care in the last 2 weeks $(50.0 \%, 30.8 \%, 43.1 \%$ in period 1, 2, and 3, respectively). Given the prolonged pandemic causing stigmatization and hatred against HCWs leading to increased prevalence of burnout, high-level interventions and supports are warranted.
\end{abstract}

Keywords: coronavirus disease 2019 (COVID-19); pandemic; burnout; prevention; intention to leave

\section{Introduction}

Since the coronavirus disease 2019 (COVID-19) emerged, the public health landscape had to go through dramatic changes. Among the struggles to fight against the virus, frontline healthcare workers (HCWs) have had significant stress and hardship since the beginning of the pandemic. As noted by the Director-General of the World Health Organization and other experts, the COVID-19 pandemic has a considerable negative effect on mental health and well-being, by exacerbating existing mental health disorders, limiting access to healthcare, and posing considerable stress and risks of infection [1-4]. With the prolonged pandemic, HCWs are at increased risk of psychiatric symptoms than the general population, including depression, anxiety, insomnia, or even suicidal ideation [5,6]. In particular, burnout is a common syndrome in HCWs amid the pandemic. While burnout syndrome is not included in the list of mental disorders in the 10th revision of the International Classification of Diseases, a study suggested its association with major mental disorders such as insomnia, depression, anxiety, and posttraumatic symptoms [7]. We previously reported that HCWs who engaged in care of COVID-19 patients had significantly higher burnout rates $(50.0 \%)$ than those who did not, and those 
working in the intensive care unit were more likely to have experienced burnout than those in floors [8]. The study was done amid the third surge of the COVID-19 cases in Japan in November 2020. Unfortunately, the country has had to go through two more significant surges of cases since then [9]. Given the uncertainty concerning how long the COVID-19 pandemic may last, HCW burnout, which is a chronic psychological condition with a loss of enthusiasm and personal accomplishment, feelings of physical and mental exhaustion, and depersonalization [10], continues to be a considerable concern from the occupational and public health perspectives.

It needs to be noted that HCWs are vulnerable to burnout at the baseline, with reported prevalence in Japan around 20-30\% before the COVID-19 pandemic [11,12]. So far, studies have reported that the prevalence of burnout among HCWs has further increased in various countries during the pandemic [13-24]. A recent systematic review and meta-analysis that quantified the psychological symptoms among frontline HCWs during pandemics noted that the prevalence of burnout was 31.8\% [25]. In addition, Kok et al. reported in their longitudinal cohort study that HCWs working in intensive care units experienced worsening burnout symptoms during the COVID-19 pandemic compared to the prepandemic periods [26]. However, no reports are available if the prevalence of burnout increases over time during the pandemic.

Amid the prolonged fight against the virus, frustration became pervasive among the general public in Japan, which occasionally turned into hatred and discrimination against HCWs $[27,28]$. Given the stress from the pandemic and COVID-19 patient care themselves as well as the discrimination and violence, it is easily assumed that the prevalence of burnout might have gone up over the period. We aimed to explore the up-to-date prevalence of burnout in Japanese HCWs amid the ongoing COVID-19 pandemic based on a hypothesis that the prevalence may increase over time, following our previous crosssectional study in a Japanese national university hospital.

\section{Materials and Methods}

\subsection{Study Design, Setting, and Participants}

We conducted three cross-sectional studies in a fashion of anonymous, self-administered voluntary paper or web-based survey. Participants included physicians, nurses, pharmacists, clinical engineers, and physical therapists in Okayama University Hospital (OUH; a tertiary-care Japanese national university hospital with more than 800 beds). Before the initial cross-sectional study that we previously reported [8], we conducted a power analysis for two proportions to estimate a sample size required to detect the significant differences between the prevalence of burnout among those engaged in the COVID-19 patient care in the past 2 weeks compared to those who did not. We defined the prevalence of burnout in those who engaged in COVID-19 care in the period as 70\% and those who did not as $20 \%$ in the analysis based on the previous studies $[12,19,20]$. At a $5 \%$ level of significance and $80 \%$ test power, the sample size needed was estimated as $n=15$ in each group $(n=30$ as a whole). Homogenous purposive samplings were used to survey the 130 healthcare professionals who belonged to the OUH on 1 November 2020. The purposive sampling criteria included HCWs who belonged to or took care of the patients in the Department of General Medicine, Emergency Department/Intensive Care Unit (EICU), Center for Graduate Medical Education. All the participants could potentially take care of COVID-19 patients under investigation (PUI) of COVID-19. Completion of the surveys implied the participants' consent. As noted in the previous study, the survey was developed through consultation with an expert in medical education at OUH and piloting. Survey instructions and instruments were described in Japanese. All participants were invited to complete the surveys from 13-30 November 2020 (period 1), 15-28 February 2021 (period 2), and 18-31 May 2021 (period 3), in Japan Standard Time. Of note, the hospital faced significant surges of COVID-19 cases during periods 1 and 3, and fewer COVID-19 patients were hospitalized in period 2 since Japan was in the post-third surge period in February 2021. We provided no financial incentives for their participation in the survey. The survey items included basic demographics such as gender, job category, affiliation, years of experience, 
size of household, and a COVID-19 related item (e.g., "Have you engaged in care of patients with COVID-19 or PUI of COVID-19 in the past 2 weeks?"). We did not collect their ages to protect participants' anonymity.

\subsection{Measurements}

The Maslach Burnout Index (MBI)

We measured burnout with the Japanese translation of the Maslach Burnout InventoryHuman Services Survey (MBI-HSS). The instrument was validated to measure burnout in Japanese HCWs by Higashiguchi et al. [29]. It has 22 items with three domains: emotional exhaustion (EE), depersonalization (DP), and personal accomplishment (PA). Each item has a 7-point Likert scale from "never" or 0 to "daily" or 6 . Based on a previous study that tried to find the most commonly used raw score cut-off, we defined a 27 or higher EE score and a 10 or higher DP score (the most common cut-off) as burnout [30]. Maslach et al. noted that PA was an independent subscale without correlation with EE and DP subscales. Thus, we did not use low PA scores (33 or lower; the most commonly used cut-off) to define burnout [31].

\subsection{Statistical Analysis}

Data analysis was performed with JMP version 15.1.0 (SAS Institute Inc., Cary, NC, USA). Mann-Whitney U test was chosen to examine differences in the time participants' MBI scores given its non-normal distribution. We used Fisher's exact test for associations between categorical variables. We employed logistic regression analyses to evaluate factors associated with burnout. The threshold for significance was defined as $p<0.05$.

\section{Results}

Response rates to the surveys were 33 out of $130(25.4 \%)$ in period 1,36 out of $130(27.7 \%)$ in period 2, and 56/162 (34.6\%) in period 3, respectively, for the included HCWs. Participants' demographic characteristics for each survey are summarized in Table 1. Throughout the periods, similar results were observed regarding the mean years of experience of the participants (mean 11.0-11.5 years), gender balances, or household size. Of note, compared to period 1, more participants belonged to EICU in period 2. In period 3, 19/56 (34.0\%) participants noted themselves as "others" regarding affiliations. Those who answered "others" in the question included floating nurses working in COVID-19 dedicated units. Participants' job categories differed between the periods; in periods 1 and 3, 60-70\% of the participants were nurses, whereas physicians were dominant $(17 / 36(47.2 \%))$ in period 2 . Over the study periods, more respondents were involved in the COVID-19 patient care. In period 1, 12/33 (36.4\%) were engaged in care of COVID-19 patients or COVID-19 PUI in the past 2 weeks, whereas 26/36 $(72.2 \%)$ in period 2 and $51 / 56(91.1 \%)$ in period 3 answered that they worked for COVID-19 patients in the designated periods, respectively.

Table 2 summarize respondents' answers to the MBI and the prevalence of burnout. Although the scores of EE and DP were higher in those who engaged in care of COVID-19 patients or PUI in periods 1 and 3, no statistically significant differences were noted in the measures throughout the periods compared to those who did not engage in the care of COVID-19 patients or PUI in the past 2 weeks. The mean PA scores (higher score suggests a feeling of better self-accomplishment) were higher in those who engaged in COVID-19 patient care than those who did not consistently without statistically significant differences.

Except for period 1 when the prevalence of burnout was significantly higher in those engaged in the care of COVID-19 care in the last 2 weeks compared to those who did not $(50.0 \%$ vs. $9.5 \%, p=0.016)$, no significant changes in the prevalence of burnout was observed in HCWs involved in COVID-19 patient care compared to those did not in period 2 or 3 . Of note, however, in period 3 when most of the respondents were engaged in COVID-19 patient care, 22/51 (43.1\%) experienced burnout at the time of the survey. No consistent tendency in the prevalence of burnout based on variables was observed throughout the periods (Table 3). However, those engaged in COVID-19 patient care in the last 2 weeks were more likely to experience burnout in periods 1 and 3 . 
Table 1. Demographic characteristics of the study participants.

\begin{tabular}{|c|c|c|c|c|c|c|c|c|c|}
\hline \multirow[t]{2}{*}{ Characteristic } & \multicolumn{3}{|c|}{$\begin{array}{l}\text { Period } 1 \\
11 / 2020\end{array}$} & \multicolumn{3}{|c|}{$\begin{array}{c}\text { Period } 2 \\
2 / 2021\end{array}$} & \multicolumn{3}{|c|}{$\begin{array}{c}\text { Period } 3 \\
5 / 2021\end{array}$} \\
\hline & Value & SD & $95 \%$ CI & Value & SD & $95 \% \mathrm{CI}$ & Value & SD & $95 \% \mathrm{CI}$ \\
\hline \multicolumn{10}{|l|}{ Years in experience } \\
\hline Mean & 11.5 & 8.2 & $8.6-14.4$ & 11.0 & 6.9 & $8.7-13.3$ & 11.0 & 8.2 & $8.8-13.1$ \\
\hline \multicolumn{10}{|l|}{ Gender, no. (\%) } \\
\hline Female & $24(72.7)$ & & & $24(66.7)$ & & & $42(75.0)$ & & \\
\hline \multicolumn{10}{|l|}{ Affiliation, no. (\%) } \\
\hline Emergency department/Intensive care unit & $8(24.2)$ & & & $17(47.2)$ & & & $10(17.9)$ & & \\
\hline General Medicine & $24(72.7)$ & & & $15(41.7)$ & & & $27(48.2)$ & & \\
\hline Others & $1(0.3)$ & & & $4(11.1)$ & & & $19(34.0)$ & & \\
\hline \multicolumn{10}{|l|}{ Job category, no. (\%) } \\
\hline Physician & $11(33.3)$ & & & $17(47.2)$ & & & $14(25.0)$ & & \\
\hline Nurse & $21(63.6)$ & & & $13(36.1)$ & & & $39(69.6)$ & & \\
\hline Clinical engineer & $1(0.3)$ & & & $2(5.6)$ & & & 0 & & \\
\hline Physical therapist & 0 & & & $2(5.6)$ & & & $3(5.4)$ & & \\
\hline \multicolumn{10}{|l|}{ Size of household } \\
\hline Mean & 2.2 & 1.1 & $1.8-2.6$ & 2.5 & 1.4 & $2.1-3.0$ & 2.2 & 1.2 & $1.8-2.5$ \\
\hline \multicolumn{10}{|c|}{$\begin{array}{l}\text { Engaged in care of COVID-19 patients or COVID-19 PUI in } \\
\text { the past } 2 \text { weeks, no. }(\%)\end{array}$} \\
\hline No & $21(63.6)$ & & & $10(27.8)$ & & & $5(8.9)$ & & \\
\hline Yes & $12(36.4)$ & & & $26(72.2)$ & & & $51(91.1)$ & & \\
\hline Total number of participants & 33 & & & 36 & & & 56 & & \\
\hline
\end{tabular}


Table 2. Results of the Maslach Burnout Index.

\begin{tabular}{|c|c|c|c|c|c|c|c|c|c|c|c|c|c|c|c|}
\hline \multirow{3}{*}{ Measure } & \multicolumn{5}{|c|}{$\begin{array}{c}\text { Period } 1 \\
11 / 2020\end{array}$} & \multicolumn{5}{|c|}{$\begin{array}{c}\text { Period } 2 \\
2 / 2021\end{array}$} & \multicolumn{5}{|c|}{$\begin{array}{c}\text { Period } 3 \\
5 / 2021\end{array}$} \\
\hline & \multicolumn{2}{|c|}{$\begin{array}{c}\text { Engaged in } \\
\text { COVID-19 Care in } \\
\text { the Last } 2 \text { Weeks } \\
\quad(n=12)\end{array}$} & \multicolumn{2}{|c|}{$\begin{array}{l}\text { Not Engaged in } \\
\text { COVID-19 Care in } \\
\text { the Last } 2 \text { Weeks } \\
(n=21)\end{array}$} & \multirow[t]{2}{*}{$p$-Value } & \multicolumn{2}{|c|}{$\begin{array}{c}\text { Engaged in } \\
\text { COVID-19 Care in } \\
\text { the Last } 2 \text { Weeks } \\
(n=26)\end{array}$} & \multicolumn{2}{|c|}{$\begin{array}{l}\text { Not Engaged in } \\
\text { COVID-19 Care in } \\
\text { the Last } 2 \text { Weeks } \\
(n=10)\end{array}$} & \multirow[t]{2}{*}{$p$-Value } & \multicolumn{2}{|c|}{$\begin{array}{c}\text { Engaged in } \\
\text { COVID-19 Care in } \\
\text { the Last } 2 \text { Weeks } \\
(n=51)\end{array}$} & \multicolumn{2}{|c|}{$\begin{array}{l}\text { Not Engaged in } \\
\text { COVID-19 Care in } \\
\text { the Last } 2 \text { Weeks } \\
(n=5)\end{array}$} & \multirow[t]{2}{*}{$p$-Value } \\
\hline & Median & IQR & Median & IQR & & Median & IQR & Median & IQR & & Median & IQR & Median & IQR & \\
\hline $\mathrm{EE}$ & 24.0 & $14.3-38.0$ & 18.0 & $12.5-23.5$ & 0.116 & 17.0 & $12.0-28.5$ & 23.0 & $8.0-30.3$ & 0.915 & 20.0 & $12.0-31.0$ & 13.0 & $6.5-28.0$ & 0.238 \\
\hline $\mathrm{DP}$ & 4.5 & $2.3-12.3$ & 4.0 & $0.5-6.5$ & 0.207 & 2.5 & $1.0-6.5$ & 4.0 & $3.8-5.3$ & 0.255 & 5.0 & $1.0-12.0$ & 5.0 & $1.5-7.5$ & 0.806 \\
\hline PA & 27.5 & $20.0-36.0$ & 20.0 & $16.5-28.5$ & 0.088 & 24.5 & $18.8-32.3$ & 23.0 & $15.0-25.5$ & 0.313 & 25.0 & $19.0-30.0$ & 15.0 & $11.0-34.5$ & 0.446 \\
\hline \multicolumn{16}{|c|}{ Measure (No. (\%)) } \\
\hline Burnout & & & & & 0.016 & & & & & 0.964 & & & & & 0.295 \\
\hline Yes & \multicolumn{2}{|c|}{$6(50.0)$} & \multicolumn{2}{|c|}{$2(9.5)$} & & \multicolumn{2}{|c|}{$8(30.8)$} & \multicolumn{2}{|c|}{$3(30.0)$} & & \multicolumn{2}{|c|}{$22(43.1)$} & \multicolumn{2}{|c|}{$1(20.0)$} & \\
\hline $\mathrm{EE} \geq 27$ & \multicolumn{2}{|c|}{$3 / 6(50.0)$} & \multicolumn{2}{|c|}{$2 / 2(100)$} & & \multicolumn{2}{|c|}{$7 / 8(87.5)$} & \multicolumn{2}{|c|}{$3 / 3(100)$} & & \multicolumn{2}{|c|}{$19 / 22(86.4)$} & \multicolumn{2}{|c|}{$1 / 1(100)$} & \\
\hline $\mathrm{DP} \geq 10$ & \multicolumn{2}{|c|}{$4 / 6(66.7)$} & \multicolumn{2}{|c|}{$1 / 2(50.0)$} & & \multicolumn{2}{|c|}{$4 / 8(50.0)$} & \multicolumn{2}{|c|}{$0 / 3(0)$} & & \multicolumn{2}{|c|}{$15 / 22(68.2)$} & \multicolumn{2}{|c|}{$1 / 1(100)$} & \\
\hline No & \multicolumn{2}{|c|}{$6(50.0)$} & \multicolumn{2}{|c|}{$19(90.5)$} & & \multicolumn{2}{|c|}{$18(69.2)$} & 7( & 70.0) & & 29 & (56.9) & $4(8$ & 30.0) & \\
\hline
\end{tabular}

Abbreviations: CI, confidence interval. The base date of the "last 2 weeks" is the day when the participants answered the surveys. $p$-value is calculated with Mann-Whitney U test or Fisher's exact test. 
Table 3. Prevalence of burnout depending on variables based on logistic regression analyses.

\begin{tabular}{|c|c|c|c|c|c|c|}
\hline \multirow[t]{2}{*}{ Variable } & \multicolumn{2}{|c|}{$\begin{array}{l}\text { Period } 1 \\
11 / 2020\end{array}$} & \multicolumn{2}{|c|}{$\begin{array}{c}\text { Period } 2 \\
2 / 2021\end{array}$} & \multicolumn{2}{|c|}{$\begin{array}{c}\text { Period } 3 \\
5 / 2021\end{array}$} \\
\hline & OR (95\% CI) & $p$-Value & OR (95\% CI) & $p$-Value & OR $(95 \%$ CI $)$ & $p$-Value \\
\hline \multicolumn{7}{|l|}{ Gender } \\
\hline Male & (Reference) & NA & (Reference) & NA & (Reference) & NA \\
\hline Female & $0.53(0.10-2.8)$ & 0.651 & $2.1(0.49-9.4)$ & 0.446 & $1.35(0.39-4.7)$ & 0.639 \\
\hline \multicolumn{7}{|l|}{ Job category } \\
\hline Nurse & $1.2(0.23-6.3)$ & 0.830 & $0.43(0.086-2.1)$ & 0.440 & $1.5(0.44-5.4)$ & 0.501 \\
\hline Female $\times$ Nurse * & NA & NA & NA & NA & $2.4(0.23-25.5)$ & 0.460 \\
\hline \multicolumn{7}{|l|}{ Affiliation } \\
\hline General Medicine & (Reference) & NA & (Reference) & NA & (Reference) & NA \\
\hline EICU & $6.7(1.1-42.1)$ & 0.031 & $0.62(0.13-2.9)$ & 0.699 & $1.9(0.43-8.2)$ & 0.404 \\
\hline EICU $\times$ Female & $12.0(1.2-121.6)$ & 0.035 & $0.83(0.051-13.6)$ & 0.898 & $1.0(0.16-6.2)$ & 1.00 \\
\hline \multicolumn{7}{|c|}{$\begin{array}{l}\text { Engagement in COVID-19 care } \\
\text { in the last } 2 \text { weeks }\end{array}$} \\
\hline Yes & $8.5(1.3-54.1)$ & 0.014 & $1.0(0.21-5.1)$ & 1.00 & $3.0(0.32-29.1)$ & 0.394 \\
\hline Yes $\times$ Female & $12.8(1.3-128.8)$ & 0.031 & $2.0(0.19-20.6)$ & 0.560 & $2.4(0.23-25.5)$ & 0.460 \\
\hline
\end{tabular}

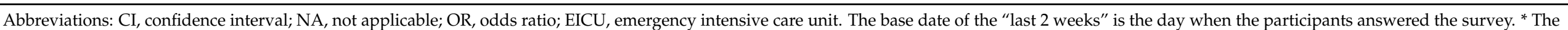
impact of gender in terms of job category and burnout were not assessed in period 1 and 2 due to the limited sample sizes. 


\section{Discussion}

In this follow-up study, we found that burnout was prevalent in $30-50 \%$ of HCWs during the periods. While there were no significant increases in the prevalence of burnout in those who were engaged in COVID-19 patients care than those who did not, interestingly, the prevalence of burnout was considerably higher during the nationwide surges of COVID-19 cases (period 1 and 3) than the post-surge period when less COVID-19 patients were hospitalized (period 2). The results suggest that patient overload and burden amid the pandemic might have contributed to the rise in burnout prevalence. Moreover, it poses a question if the current healthcare system would be sustainable given the uncertainty regarding how long the current COVID-19 pandemic may last.

Unlike our previous report, we could not find any variables related to a statistically significant increase in burnout prevalence. However, upon comparing the results from periods 1 and 3, similar tendencies were observed; nurses and those in EICU tended to have higher odds of burnout than their counterparts. While there are mixed results concerning risk factors for burnout during the COVID-19 pandemic, some literature reported that nurses were more vulnerable to burnout than physicians, especially in ICU settings [21,24,26,32]. Given that nurses are always working in the frontline of patient care throughout their shifts, the results were as expected, and hospital administrators may need to focus on nurses to prevent burnout with measures such as occupational mental health surveillance.

Previously, we discussed the problem of burnout from perspectives of promoting universal health coverage (UHC) and resilience $[8,33,34]$. The importance of UHC has been unchanged amid the pandemic; rather, it has been more critical than ever before to keep sustainable healthcare delivery. As hospitals are overwhelmed by the surge of COVID-19 patient hospitalization and death, HCWs are pressured to ration care due to lack of oxygen, hospital beds, or workforce. Due to the prolonged pandemic, the general public has been frustrated over restrictions and mandates. Unfortunately, the frustration turned into hatred, stigmatization, or attacks against HCWs [27,28,35-39] because some attribute the lack of hospital beds and care rationing to HCWs being lazy. Burnout of HCWs may be the consequence of the various issues discussed above, leading to increased leave of HCWs from hospitals. While HCWs might still need to know how to protect themselves from burnout by mitigating interventions such as counseling, reducing workload, or resilience building, most of the factors causing burnout of HCWs are beyond what an individual can handle. Organizational or policy-level approaches are needed to mentally and physically protect HCWs at this time. Especially, stigmatization and attack against HCWs should never be allowed, and strong interventions at a government level are warranted.

Moral injury is an important issue that arose during the pandemic. Originally, this term was used to describe the psychological symptoms seen in soldiers returning from war. It is defined as psychological distress caused by the fact that one's actions, or failure to act, are contrary to one's moral and ethical code [40]. Unlike common mental disorders such as depression, anxiety, or post-traumatic stress disorder (PTSD), moral injury is not categorized as a mental disorder. However, it is a syndrome sharing similarities with PTSD [41], and HCWs are at increased risk of moral injury during the COVID-19 pandemic because they have been forced to ration care amid the surges of the cases. As moral injury may be closely related to PTSD and burnout [42], early interventions such as providing education about the emotional and social challenges during the pandemic as well as reflection on HCWs' experience would be necessary.

Several limitations to this study need to be noted. First, the study was comprised of three cross-sectional surveys at a single center with small sample sizes. Thus, we may not be able to conclude causal relationships between burnout and the current COVID-19 pandemic. As discussed in our previous report, the organizational climate might be a confounding factor of the prevalence of burnout, which might have affected the results [43]. Second, while we performed multiple surveys over time, we could not perform follow-up surveys for the same individuals. A longitudinal study design still needs to be pursued to clarify the long-term effect of the pandemic. Third, the response rates of surveys were between 
25.4-34.6\%. Since those suffering from burnout might have opted out to answer the surveys, the true prevalence of burnout among HCWs might be higher than reported. Despite these limitations, our study may be the first to report the burnout prevalence of HCWs amid the COVID-19 pandemic over a year. The present study suggests that healthcare administrators and governments may need to have structured disaster management plans and support systems to mitigate the burnout of HCWs. Systematic scoping review or meta-analysis of the existing literature, or multi-center prospective cohort studies at the international level are warranted as models for future research to establish factors related to burnout among HCWs during the COVID-19 pandemic or other health emergencies.

\section{Conclusions}

Through the study, we have summarized the prevalence of burnout among HCWs during the COVID-19 pandemic over time and showed that HCWs might suffer from burnout considerably during the surges of COVID-19 cases than post-surge periods. Given the uncertainty concerning the pandemic, people are becoming more frustrated with restrictions and mandates, which has turned into stigmatization and hatred against HCWs. Exhaustion from the care of COVID-19 patients, rationing of care amid the surge of COVID-19 cases and healthcare overwhelm, and attacks against HCWs, all lead to further burnout of HCWs. In addition to personal efforts to prevent burnout, high-level interventions and support for HCWs at the government level may be essential to overcome the prolonged public health emergency.

Author Contributions: Conceptualization, Y.N. and T.M.; methodology, Y.N. and T.M.; software, Y.N.; validation, Y.N. and T.M.; formal analysis, Y.N.; investigation, Y.N.; resources, Y.N.; data curation, H.H. and F.O.; writing — original draft preparation, Y.N.; writing—review and editing, A.S., K.H., T.M., H.H., Y.K. and F.O.; supervision, F.O.; project administration, T.M. All authors have read and agreed to the published version of the manuscript.

Funding: This research received no external funding.

Institutional Review Board Statement: This study protocol was approved by the Institutional Review Board of Okayama University Hospital (reference number 2007-012).

Informed Consent Statement: Completion of the surveys implied the participants' consent.

Data Availability Statement: The datasets generated and analyzed during the current study are available from the corresponding author on reasonable request.

Acknowledgments: We thank Hitomi Ooyabu for her help with the collection of survey responses.

Conflicts of Interest: The authors declare no conflict of interest.

\section{References}

1. Adhanom Ghebreyesus, T. Addressing mental health needs: An integral part of COVID-19 response. World Psychiatry 2020, 19, 129-130. [CrossRef]

2. Fiorillo, A.; Gorwood, P. The consequences of the COVID-19 pandemic on mental health and implications for clinical practice. Eur. Psychiatry 2020, 63, e32. [CrossRef] [PubMed]

3. Marazziti, D.; Stahl, S.M. The relevance of COVID-19 pandemic to psychiatry. World Psychiatry 2020, 19, 261. [CrossRef]

4. Unützer, J.; Kimmel, R.J.; Snowden, M. Psychiatry in the age of COVID-19. World Psychiatry 2020, 19, 130-131. [CrossRef] [PubMed]

5. Gorwood, P.; Fiorillo, A. One year after the COVID-19: What have we learnt, what shall we do next? Eur. Psychiatry 2021, 64, e15. [CrossRef]

6. Kuzman, M.R.; Curkovic, M.; Wasserman, D. Principles of mental health care during the COVID-19 pandemic. Eur. Psychiatry 2020, 63, e45. [CrossRef] [PubMed]

7. Ghio, L.; Patti, S.; Piccinini, G.; Modafferi, C.; Lusetti, E.; Mazzella, M.; Del Sette, M. Anxiety, depression and risk of post-traumatic stress disorder in health workers: The relationship with burnout during COVID-19 pandemic in Italy. Int. J. Environ. Res. Public Health 2021, 18, 9929. [CrossRef]

8. Nishimura, Y.; Miyoshi, T.; Hagiya, H.; Kosaki, Y.; Otsuka, F. Burnout of healthcare workers amid the COVID-19 pandemic: A Japanese cross-sectional survey. Int. J. Environ. Res. Public Health 2021, 18, 2434. [CrossRef] [PubMed] 
9. Covid19 japan on GitHub. Japan COVID-19 Coronavirus Tracker. Available online: https://covid19japan.com/ (accessed on 6 September 2021).

10. Aronsson, G.; Theorell, T.; Grape, T.; Hammarstrom, A.; Hogstedt, C.; Marteinsdottir, I.; Skoog, I.; Traskman-Bendz, L.; Hall, C. A systematic review including meta-analysis of work environment and burnout symptoms. BMC Public Health 2017, 17, 264. [CrossRef]

11. Maslach, C.; Leiter, M.P. New insights into burnout and health care: Strategies for improving civility and alleviating burnout. Med. Teach. 2017, 39, 160-163. [CrossRef] [PubMed]

12. Nishimura, Y.; Miyoshi, T.; Obika, M.; Ogawa, H.; Kataoka, H.; Otsuka, F. Factors related to burnout in resident physicians in Japan. Int. J. Med. Educ. 2019, 10, 129-135. [CrossRef]

13. Celmece, N.; Menekay, M. The effect of stress, anxiety and burnout levels of healthcare professionals caring for COVID-19 patients on their quality of life. Front. Psychol 2020, 11, 597624. [CrossRef]

14. Correia, I.; Almeida, A.E. Organizational justice, professional identification, empathy, and meaningful work during COVID-19 pandemic: Are they burnout protectors in physicians and nurses? Front. Psychol. 2020, 11, 566139. [CrossRef]

15. Elhadi, M.; Msherghi, A.; Elgzairi, M.; Alhashimi, A.; Bouhuwaish, A.; Biala, M.; Abuelmeda, S.; Khel, S.; Khaled, A.; Alsoufi, A.; et al. Burnout syndrome among hospital healthcare workers during the COVID-19 pandemic and civil war: A cross-sectional study. Front. Psychiatry 2020, 11, 579563. [CrossRef] [PubMed]

16. Liu, X.; Chen, J.; Wang, D.; Li, X.; Wang, E.; Jin, Y.; Ma, Y.; Yu, C.; Luo, C.; Zhang, L.; et al. COVID-19 outbreak can change the job burnout in health care professionals. Front. Psychiatry 2020, 11, 563781. [CrossRef] [PubMed]

17. Matsuo, T.; Kobayashi, D.; Taki, F.; Sakamoto, F.; Uehara, Y.; Mori, N.; Fukui, T. Prevalence of health care worker burnout during the coronavirus disease 2019 (COVID-19) pandemic in Japan. JAMA Netw Open 2020, 3, e2017271. [CrossRef]

18. Miguel-Puga, J.A.; Cooper-Bribiesca, D.; Avelar-Garnica, F.J.; Sanchez-Hurtado, L.A.; Colin-Martinez, T.; Espinosa-Poblano, E.; Anda-Garay, J.C.; Gonzalez-Diaz, J.I.; Segura-Santos, O.B.; Vital-Arriaga, L.C.; et al. Burnout, depersonalization, and anxiety contribute to post-traumatic stress in frontline health workers at COVID-19 patient care, a follow-up study. Brain Behav. 2020, 11, e02007. [PubMed]

19. Naldi, A.; Vallelonga, F.; Di Liberto, A.; Cavallo, R.; Agnesone, M.; Gonella, M.; Sauta, M.D.; Lochner, P.; Tondo, G.; Bragazzi, N.L.; et al. COVID-19 pandemic-related anxiety, distress and burnout: Prevalence and associated factors in healthcare workers of North-West Italy. BJPsych Open 2021, 7, e27. [CrossRef]

20. Tan, B.Y.Q.; Kanneganti, A.; Lim, L.J.H.; Tan, M.; Chua, Y.X.; Tan, L.; Sia, C.H.; Denning, M.; Goh, E.T.; Purkayastha, S.; et al. Burnout and associated factors among health care workers in singapore during the COVID-19 pandemic. J. Am. Med. Dir. Assoc. 2020, 21, 1751-1758.e5. [CrossRef]

21. Brera, A.S.; Arrigoni, C.; Dellafiore, F.; Odone, A.; Magon, A.; Nania, T.; Pittella, F.; Palamenghi, L.; Barello, S.; Caruso, R. Burnout syndrome and its determinants among healthcare workers during the first wave of the Covid-19 outbreak in Italy: A cross-sectional study to identify sex-related differences. Med. Lav. 2021, 112, 306-319.

22. Dionisi, T.; Sestito, L.; Tarli, C.; Antonelli, M.; Tosoni, A.; D’Addio, S.; Mirijello, A.; Vassallo, G.A.; Leggio, L.; Gasbarrini, A.; et al. Risk of burnout and stress in physicians working in a COVID team: A longitudinal survey. Int. J. Clin. Pract. 2021, 1, e14755.

23. Lim, K.H.J.; Murali, K.; Kamposioras, K.; Punie, K.; Oing, C.; O'Connor, M.; Thorne, E.; Amaral, T.; Garrido, P.; Lambertini, M.; et al. The concerns of oncology professionals during the COVID-19 pandemic: Results from the ESMO resilience task force survey II. ESMO Open 2021, 6, 100199. [CrossRef] [PubMed]

24. Zhang, X.; Wang, J.; Hao, Y.; Wu, K.; Jiao, M.; Liang, L.; Gao, L.; Ning, N.; Kang, Z.; Shan, L.; et al. Prevalence and factors associated with burnout of frontline healthcare workers in fighting against the COVID-19 pandemic: Evidence from china. Front. Psychol. 2021, 12, 680614. [CrossRef]

25. Busch, I.M.; Moretti, F.; Mazzi, M.; Wu, A.W.; Rimondini, M. What we have learned from two decades of epidemics and pandemics: A systematic review and meta-analysis of the psychological burden of frontline healthcare workers. Psychother. Psychosom. 2021, 90, 178-190. [CrossRef] [PubMed]

26. Kok, N.; van Gurp, J.; Teerenstra, S.; van der Hoeven, H.; Fuchs, M.; Hoedemaekers, C.; Zegers, M. Coronavirus disease 2019 immediately increases burnout symptoms in ICU professionals: A longitudinal cohort study. Crit. Care Med. 2021, 49, 419-427. [CrossRef] [PubMed]

27. Kyodo News. Frontline Health Workers in Japan Face Discrimination over Virus. Available online: https: / / english.kyodonews. net/news/2020/05/4a48fb130fd9-feature-frontline-health-workers-in-japan-face-discrimination-over-virus.html (accessed on 6 September 2021).

28. Shimizu, K.; Lin, L. Defamation against healthcare workers during COVID-19 pandemic. Int. J. Health Policy Manag. 2020. [CrossRef] [PubMed]

29. Higashiguchi, K.; Morikawa, Y.; Miura, K.; Nishijo, M.; Tabata, M.; Yoshita, K.; Sagara, T.; Nakagawa, H. The development of the Japanese version of the Maslach Burnout Inventory and the examination of the factor structure. Nihon Eiseigaku Zasshi 1998, 53, 447-455. [CrossRef]

30. Doulougeri, K.; Georganta, K.; Montgomery, A.A. “Diagnosing” burnout among healthcare professionals: Can we find consensus? Cogent Med. 2016, 3, 1. [CrossRef]

31. Maslach, C.; Jackson, S.E. The measurement of experienced burnout. J. Organ. Behav. 1981, 2, 99-113. [CrossRef] 
32. Ohue, T.; Togo, E.; Ohue, Y.; Mitoku, K. Mental health of nurses involved with COVID-19 patients in Japan, intention to resign, and influencing factors. Medicine 2021, 100, e26828. [CrossRef] [PubMed]

33. Matsumura, H.; Nishimura, Y.; Horiuchi, H.; Higashiraa, T.; Kita, Y.; Nishizawab, H. G20 okayama health ministersmeeting: Lessons learned and way forward. Glob. Health Med. 2019, 1, 65-70. [CrossRef]

34. Nishizawa, H.; Nishimura, Y.; Matsumura, H.; Horiuchi, H.; Higashira, T.; Kita, Y.; Sahara, Y.; Suzuki, Y. G20 Okayama Health Ministers' Meeting: Conclusions and commitments. J. Glob. Health 2020, 10, 010320. [CrossRef] [PubMed]

35. Devi, S. COVID-19 exacerbates violence against health workers. Lancet 2020, 396, 658. [CrossRef]

36. McKay, D.; Heisler, M.; Mishori, R.; Catton, H.; Kloiber, O. Attacks against health-care personnel must stop, especially as the world fights COVID-19. Lancet 2020, 395, 1743-1745. [CrossRef]

37. Rebecca, R. From Heroes to Villains: Health Care Workers Targeted in Coronavirus-Related Attacks. Available online: https: / / www.devex.com/news/from-heroes-to-villains-health-care-workers-targeted-in-coronavirus-related-attacks-97963 (accessed on 6 September 2021).

38. Jecker, N.S.; Takahashi, S. Shaming and stigmatizing healthcare workers in Japan during the COVID-19 pandemic. Public Health Ethics 2021, phab003. [CrossRef]

39. Larkin, H. Navigating attacks against health care workers in the COVID-19 era. JAMA 2021, 325, 1822. [CrossRef] [PubMed]

40. Jones, E. Moral injury in a context of trauma. Br. J. Psychiatry 2020, 216, 127-128. [CrossRef] [PubMed]

41. Levi-Belz, Y.; Greene, T.; Zerach, G. Associations between moral injury, PTSD clusters, and depression among Israeli veterans: A network approach. Eur. J. Psychotraumatol. 2020, 11, 1736411. [CrossRef]

42. Greenberg, N.; Docherty, M.; Gnanapragasam, S.; Wessely, S. Managing mental health challenges faced by healthcare workers during covid-19 pandemic. BMJ 2020, 368, m1211. [CrossRef]

43. Thompson, L.; Rose, J. Does organizational climate impact upon burnout in staff who work with people with intellectual disabilities? A systematic review of the literature. J. Intellect. Disabil. 2011, 15, 177-193. [CrossRef] 